\title{
BMJ Open Differentiating the cognitive development of early-term births in infants and toddlers: a cross-sectional study in China
}

\author{
Jing Hua, ${ }^{1}$ Jie Sun, ${ }^{1}$ Zhijuan Cao, ${ }^{1}$ Xiaotian Dai, ${ }^{1}$ Senran Lin, ${ }^{1}$ Jialin Guo, ${ }^{1}$ \\ Guixiong $\mathrm{Gu}^{2}$ Wenchong $\mathrm{Du}^{3}$
}

To cite: Hua J, Sun J, Cao Z, et al. Differentiating the cognitive development of early-term births in infants and toddlers: a cross-sectional study in China. BMJ Open 2019;9:e025275. doi:10.1136/ bmjopen-2018-025275

- Prepublication history for this paper is available online. To view these files please visit the journal online (http://dx.doi org/10.1136/bmjopen-2018025275).

$\mathrm{JH}, \mathrm{JS}, \mathrm{ZC}$ and JG contributed equally.

Received 9 July 2018 Revised 22 February 2019 Accepted 25 February 2019

Check for updates

(c) Author(s) (or their employer(s)) 2019. Re-use permitted under CC BY-NC. No commercial re-use. See rights and permissions. Published by BMJ.

${ }^{1}$ The Women and Children's Health Care Department, Shanghai First Maternity and Infant Hospital, Tongji University School of Medicine, Shanghai,

China

${ }^{2}$ Health Statistical Division,

Pediatrics Research Institution of Soochow University, Suzhou, China

${ }^{3}$ Psychology Division, Nottingham Trent University, Nottingham, UK

Correspondence to Dr Jing Hua; szhuaj@hotmail.com and Professor Guixiong Gu; szggx000@163.com

\section{ABSTRACT}

Objectives This study aimed to explore the cognitive development of low-risk children during early childhood for early-term births at 37 and 38 weeks of gestation compared with full term births at 39-41 weeks of gestation.

Setting and participants We conducted a cross-sectional study in Shanghai, one of the largest cities in China. A total of 1444 children from singleton pregnancies born at term gestation were included in the study.

Measures The cognitive outcomes of the subjects were measured using the cognitive subtest of Bayley Scales of Infant and Toddler Development, Third Edition (BSID-III) across three cities in China. We analysed the association between gestational age and cognitive development during infancy and toddler stages using multivariate linear modelling.

Results The cognitive development scores for infants born at 37 gestational weeks were significantly lower than those born at 39-41 gestational weeks $(\beta=-2.257$, $95 \% \mathrm{Cl}-4.280$ to $-0.235 ; \mathrm{p}<0.05$ ) after adjusting for children's and maternal characteristics, as well as socioeconomic factors. However, there were no significant differences in cognitive ability between infants born at 38 gestational weeks compared with their full-term counterparts $(p>0.05)$. Moreover, these effects were not found in toddlers (between 17 and 48 months of age) after adjusting for the possible confounders ( $p>0.05$ ).

Conclusions Infants born at 37 weeks of gestation exhibited weaker cognitive ability compared with those born at 39-41 weeks of gestation. Our findings provide evidences for the close monitoring of potential developmental problems in early-term children, especially those born at 37 gestational weeks.

\section{INTRODUCTION}

It had been previously believed that children born between 37 and 41 weeks of gestational age share similar health outcomes, therefore including them in the same low-risk group. ${ }^{1}$ In 2012, the American Academy of Pediatrics recommended that births occurring between 37 weeks 0 days and 38 weeks 6 days be defined as early term, while those
Strengths and limitations of this study

- Our findings extend the limited available literature on the relationship of gestational age with cognitive developmental scores. Infants born at 37 weeks of gestation had a significantly weaker cognitive ability compared with their full-term counterparts.

- Our findings provided evidences for the close monitoring of potential developmental problems in early-term children, especially in those born at 37 gestational weeks.

- The sample size was relatively small in our study $(n=1444)$, and the results were not consistent across different age groups. Further studies are needed to verify these results.

- Although we examined a number of potential confounders, several other confounding factors were not measured. For instance, the detailed maternal and obstetric factors for early-term deliveries were not available in our study.

from 39 weeks 0 days to 40 weeks 6 days as full term. ${ }^{2}$ Approximately $27.6 \%$ of all births in the USA are early term, ${ }^{3}{ }^{4}$ far exceeding the number of preterm births. ${ }^{45}$ Many studies have reported that early-term births are associated with higher neonatal morbidity and higher probability of neonatal intensive care unit admission compared with their full-term counterparts ( $>38$ gestational weeks) ${ }^{6}$ Earlyterm children also have increased susceptibility to various metabolic, neurological and respiratory diseases. ${ }^{7-9}$

Recently, research into the effect of gestational age on developmental outcomes has directed attention to the investigation of early-term infants. ${ }^{10}$ There have been increasing reports which show that early-term births resulted in worsened cognitive and academic outcomes compared with those born at 39 weeks or later. ${ }^{10-13}$ A systematic review showed that full-term cohorts performed $3 \%$ of an SD higher in cognitive 
outcome than early-term cohorts. ${ }^{10}$ The gestation period between 37 and 40 weeks was associated with neuromotor and cognitive development in infants aged 9-15 weeks and 12 months. ${ }^{13}{ }^{14}$ Early-term birth was associated with an increased risk of worsened academic achievements at ages $5-7$ years. ${ }^{15} 16$

However, on the basis of recent research, ${ }^{1317-19}$ the exact boundary which separates early-term and full-term gestation periods should be carefully examined because of its implications for neonatal and developmental outcomes. The highest risk of mortality was observed for children born at 37 gestational weeks, but not for those born at 38 gestational weeks. ${ }^{19}$ Furthermore, a prospective cohort study in Belarus showed that children born at 37 gestational weeks had a significantly lower full-scale IQ score compared with those born at 39-41 weeks, however, this difference was not observed in children born at 38 gestational weeks. ${ }^{20}$ Moreover, in a large sample of healthy infants, there was a significant difference in the mental development index between infants born at 37 and 38 gestational weeks, but almost no difference between those born at 38 and 39 gestational weeks. ${ }^{13}$ However, the degree to which earlier gestational age confers risk among infants born at term from 37 to 41 weeks of gestation remains unclear. ${ }^{71220}$

In this study, we used a cross-sectional study design to examine a sample of urban Chinese singleton pregnancies born at term gestation. We hypothesised that earlyterm births may result in significant cognitive delay, especially those born at 37 gestational weeks. We further examined the differences in cognitive ability in both infants and toddlers across various term births in order to determine the true underlying risk across different gestational weeks. The aim of the study is (1) to differentiate the cognitive development of children born at 37,38 and 39-41 gestational weeks; (2) to independently analyse the effects of gestational weeks on cognitive development in both short term (infants) and long term (toddlers), in order to provide evidences for the close monitoring of potential developmental problems in early-term children.

\section{MATERIALS AND METHODS \\ Participants}

We conducted a cross-sectional study in mainland China from May to December of 2011. We used a stratified sampling technique, with area, gender and months of age as stratification variables. A total of 1589 children aged between 16 days and 42 months were selected from three children's healthcare institutions in medium-sized cities distributed across three geographic regions: North China, Middle China and East China. The selection of age bands was based on the categories proposed in the Bayley-III technical manual (totaling 48 age bands). The inclusion criteria for infants and toddlers included: singleton and born at term, born without significant medical complications, did not have a history of medical complications, and not currently diagnosed with or receiving treatment

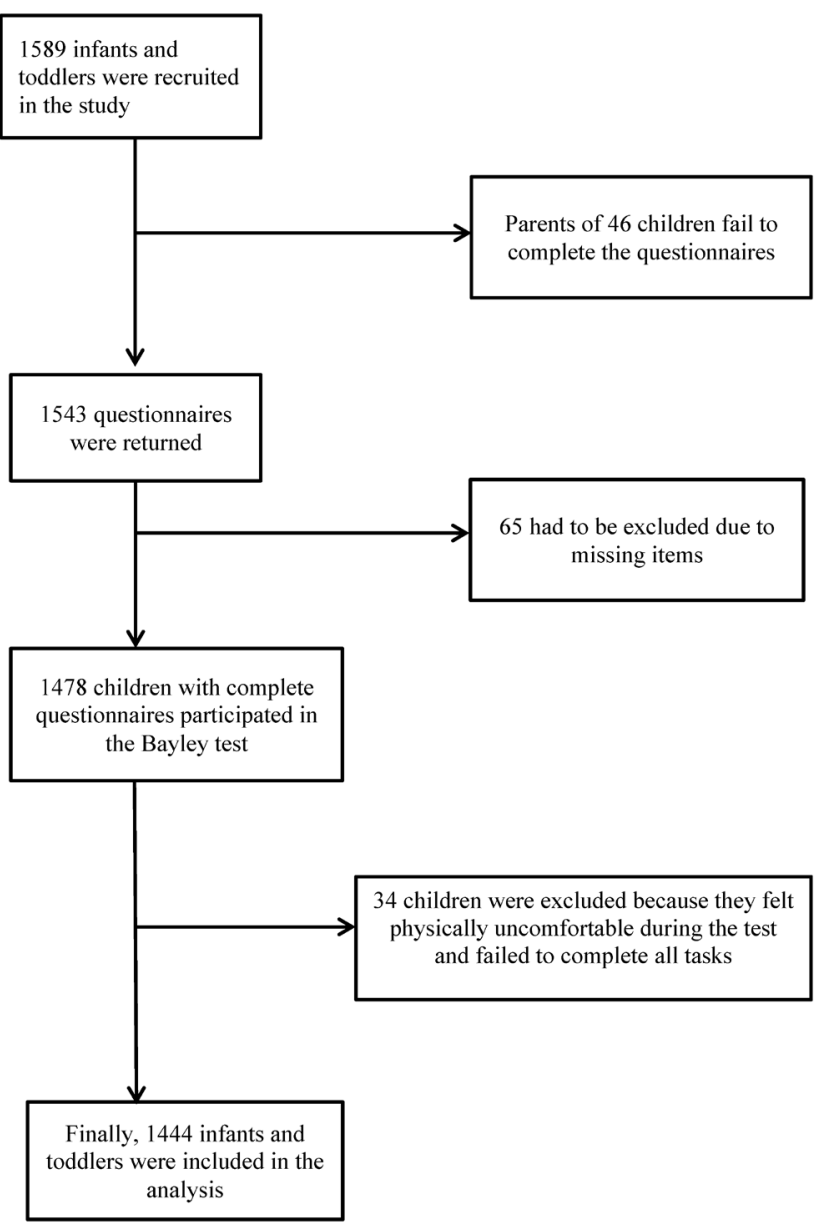

Figure 1 Number of infants and toddlers who completed the questionnaire and tests.

for mental, physical or behavioural difficulties. The exclusion criteria included: confounding conditions or developmental risk factors such as abnormal hearing or vision, taking medications that could affect performance or admission to hospital at the time of testing, and any other problems involving nutrition, sleep or infections during the clinical visit. Of the 1589 eligible children who were recruited, a total of 1444 children were included for the study (figure 1). All information was kept confidential and was only accessible to the researchers.

\section{Patient and public involvement}

None of the patients were involved in the research design or development of the research question and outcome measures. They were also not involved in the recruitment and conduct of the study. The results of the study would be disseminated to study participants by means of the participating children's healthcare institutions.

\section{Measurements}

The Bayley Scale of Infant and Toddler Development, Third Edition (BSID-III) is an individually administered scale that assesses five key developmental domains in children between 1 and 42 months of age: cognition, language (receptive and expressive communication), 
motor (gross and fine), social-emotional and adaptive behaviour. The first three domains are assessed through direct observation of the child in test situations, while the last two are assessed through questionnaires to be completed by the main caregiver. We first obtained formal permission to translate and validate the BSID-III from the American publishers of this tool (Pearson). We then started developing a Chinese version of BSID-III, following the recommendations of Hambleton and Patsula ${ }^{21}$ and Herdman, Fox-Rushby and Badia $^{22}$ for the translation and adaptation of a test, taking into consideration conceptual, item, semantic, operational, measurement and functional equivalences. Each step of this process was presented in the results section. The Chinese version of the BSID-III was translated by a native Chinese speaker and independent professional who adapted the items into context and culture. Subsequently, the final Chinese version of the BSID-III was retranslated into English by two native English speakers who were blinded to the original version. The test manual and materials will use the same trademark, logo and design as used on the English version of the test. We have explored the reliability and validity of the Bayley-III cognitive scale in a parallel study, which showed a good to excellent reliability of the Bayley-III cognitive scale (eg, the coefficients of interitem consistency were more than 0.75 ; the test-retest and inter-rater reliability of the scale were more than $0.90)$. The content, construct and known-group validity of Bayley-III cognitive scale were also sufficient in the parallel study. In addition, gestational age is measured as the age of a pregnancy which was taken from the woman's last menstrual period, records of which were obtained from the hospital's medical record registration system following confirmation by ultrasound exam.

\section{Procedure}

The survey was conducted during the well-child visits in the participating children's healthcare institutions. Nurses who took part in the check in and physical examination (weight, height and head circumference) were responsible for handing out the questionnaires to the children's parents. Six developmental paediatricians were trained to administrate the Bayley-III cognitive scale. The testers had become familiar with the test guidance by carrying out a series of practice assessments on several children who did not take part in the study. Any problems associated with test administration during the training period were clarified by the administrator of this study prior to the test. The test environment was quiet and non-interfering, and all infants and toddlers needed to be calm, stable and satiated. The tester encouraged the infants and toddlers to display their highest level of ability during the test. A trained paediatrician took the responsibility for conducting the entire test for each child in order to maximise both interpretation validity and assessment reliability.

\section{Statistical analysis}

All analyses were performed using SPSS V.17.0 software. $\mathrm{X}^{2}$ analyses were used for comparing children and maternal characteristics between those born at 37 or 38 gestational weeks and those born at full term (39-41 gestational weeks). Means of cognitive scores among different gestational weeks was evaluated using one-way analysis of variance and post hoc comparison. Multivariate linear regression was used to test the relationship between gestational age and cognitive developmental scores, taking into account potential confounding variables including gender, weight-for-length Z-scores, parity, mother's age, delivery mode, parents' education and occupation. Socioeconomic factors were not included because they were highly correlated with parental occupation. $\mathrm{P}<0.05$ was considered statistically significant.

\section{RESULTS}

Of the 1444 children included in the study, 844 were infants aged between 16 days after birth and 16 months $(58.4 \%)$, and 600 were toddlers aged between 17 months and 48 months (41.6\%). Among these subjects, 1152 $(79.8 \%)$ were full-term births, $87(6.02 \%)$ were born at 37 gestational weeks, and $205(14.2 \%)$ were born at 38 gestational weeks. The mean cognitive composite score was 101.9 with an SD of 6.9. The parity, the family's city of residence and parents' education were significantly different among those born at 37, 38 and 39-41 gestational ages (table 1 ).

The cognitive composite score was expressed as means and 95\% CI (figure 2). In infants aged between 16 days and 16 months, the cognitive composite score for those born at 37 gestational weeks of age was significantly lower than those born at 39-41 gestation weeks $(\mathrm{p}<0.05)$.

Using multivariate linear regression model, cognitive composite scores for children born at 37 weeks decreased $2.810(95 \%$ CI -4.847 to -0.774$)$ when compared with those born at 39-41 gestational weeks during infancy with statistical significance $(p=0.007)$ without adjusting for $\beta=-2.810$. The effects remained when adjusting for the children's characteristics only $(\beta=-2.723,95 \%$ CI -4.765 to $-0.680 ; p=0.009)$, or in combination with maternal characteristics $(\beta=-2.545$, $95 \%$ CI -4.590 to $-0.500 ; \mathrm{p}=0.015)$, as well as socio-economic factors $(\beta=-2.257,95 \%$ CI -4.280 to -0.235 ; $\mathrm{p}=0.029$; table 2$)$.

However, in toddlers aged between 17 months and 48 months (table 2), there were almost no statistically significant associations between those born at 37 or 38 gestational weeks and those born in full term (39-41 gestational weeks). The only difference was a slightly higher composite cognitive score ( $\beta=1.723$, 95\% CI 0.075 to $3.366 ; \mathrm{p}=0.041$ ) in toddlers born at 38 gestational weeks compared with those born in full term, when not adjusting for any other variables. The effects disappeared when adjusting the other variables. 
Table 1 Characteristics by gestational age $(n=1444)$

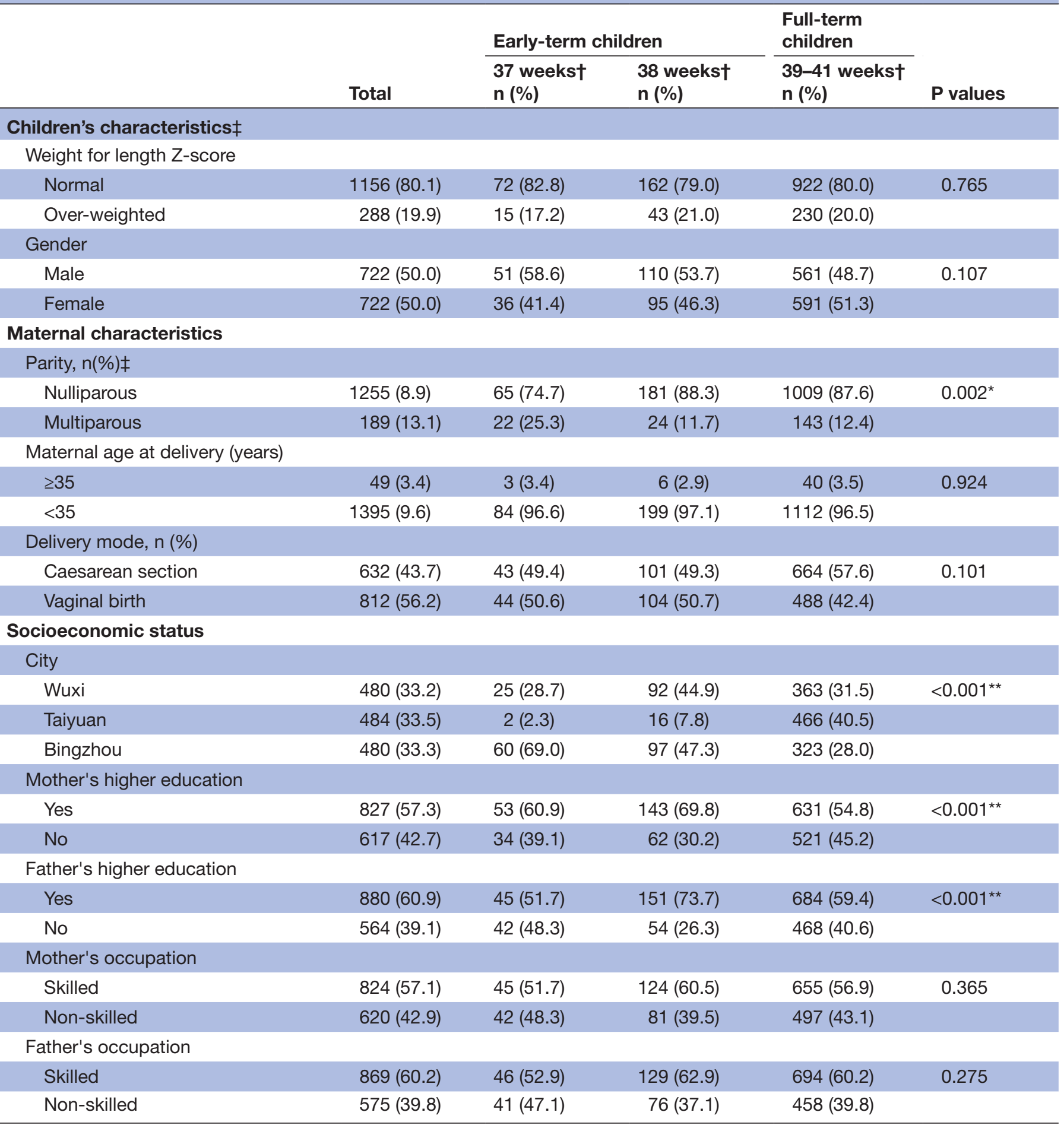

${ }^{*} \mathrm{p}<0.01 ;{ }^{* *} \mathrm{p}<0.001$.

†Gestational week.

$\ddagger \mathrm{X}^{2}$ analysis.

\section{DISCUSSION}

To our knowledge, our paper is the first in China and one of few studies in the world to report on the short- and longterm neurobehavioural outcomes of early-term children. A weaker cognitive ability was observed in infants born at 37 gestational weeks compared with their full-term (born at 39-41 gestational weeks) counterparts. Our findings extend the limited available literature on the relationship of gestational age to cognitive developmental scores.

In our study, we found that the effect of early-term birth (37 gestational weeks) persisted in infancy even when a broad range of confounders including parental 


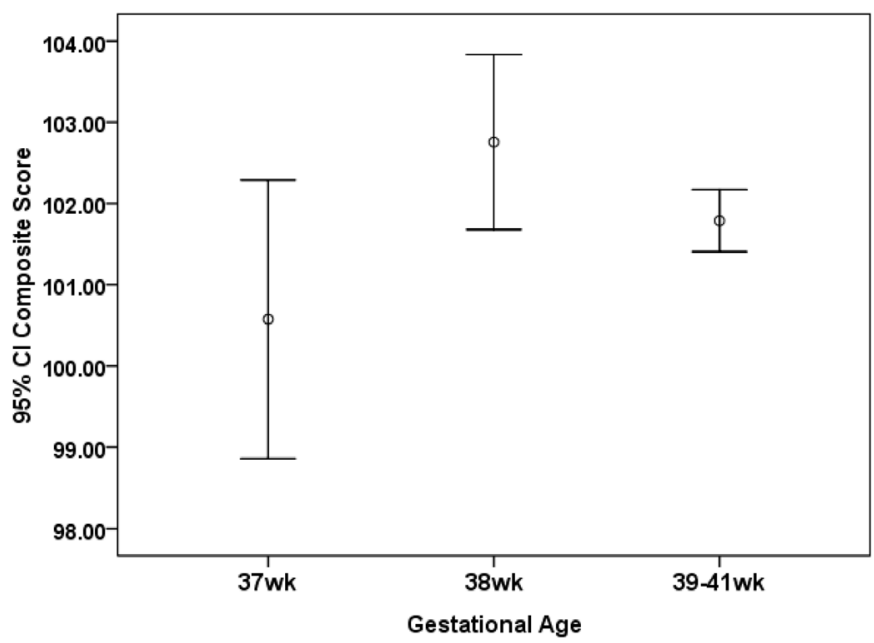

Infants and toddlers
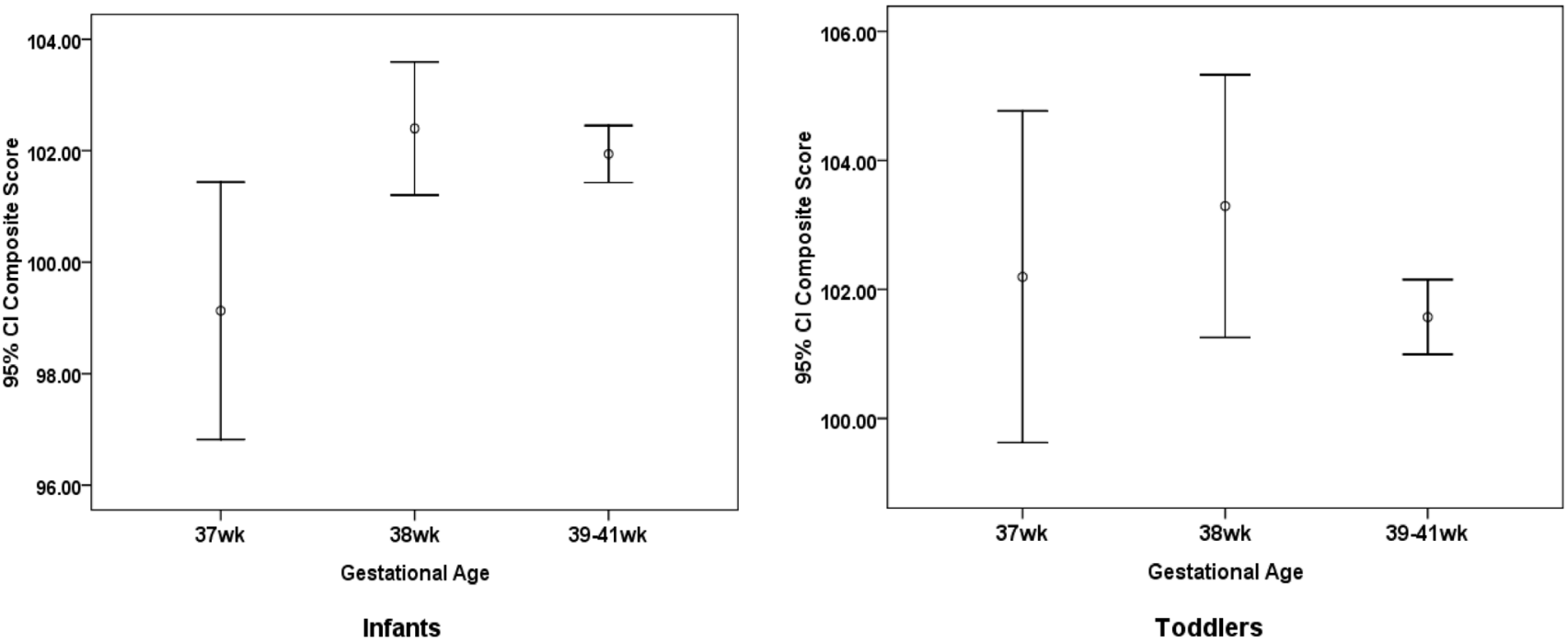

Figure 2 Cognitive composite scores by gestational week in the study are expressed as means and 95\% Cls ( $\mathrm{n}=1444)$.

characteristics were considered. The mechanisms underlying the effect of early-term birth on cognitive development scores may be multifactorial. The intrauterine and extrauterine environments differ dramatically in relationship to maternal and placental hormones, which may play an important role in brain development. ${ }^{13}$ The intrauterine environment supports typical brain development, which is more likely to be disrupted in children born during early-term gestation. ${ }^{12}$ Moreover, brain development occurs in a very specific order and time frame. ${ }^{10}$ The volume of total grey matter increases by approximately $1.4 \%$ per week from 29 to 41 weeks of gestation, while the volume of white matter sees a fivefold increase between 35 and 41 weeks of gestation. ${ }^{15}{ }^{23}$ Earlyterm births may cause disruptions at specific times during the development of the brain's neural connections for specific cognitive areas. ${ }^{24}$ Even at 38 weeks of gestation, the brain is still only $90 \%$ of full-term weight. ${ }^{25}$ However, there have been no studies about the subtle differences in brain development between infants born at 37 and 38 gestational weeks. Future research is necessary to investigate the mechanisms behind this phenomenon.

Additionally, children who were born early term may have a shorter breastfeeding duration compared with children born at full term. ${ }^{15} 26-28$ The breastfeeding duration was positively associated with children's cognitive development, ${ }^{29}{ }^{30}$ possibly due to the abundance of cognition-related nutrients found in breast milk such as docosahexaenoic and arachidonic acid. Shorter breastfeeding duration may result in an increase in morbidity such as asthma and the number of hospital admissions, which was associated with a delay in achieving early developmental milestones that may have an effect educational achievements. ${ }^{15}$

This finding further supports the results from previous related research. For example, the highest mortality rate was observed among children born at 37 weeks of gestation, which necessitates caution in inducing labour for 


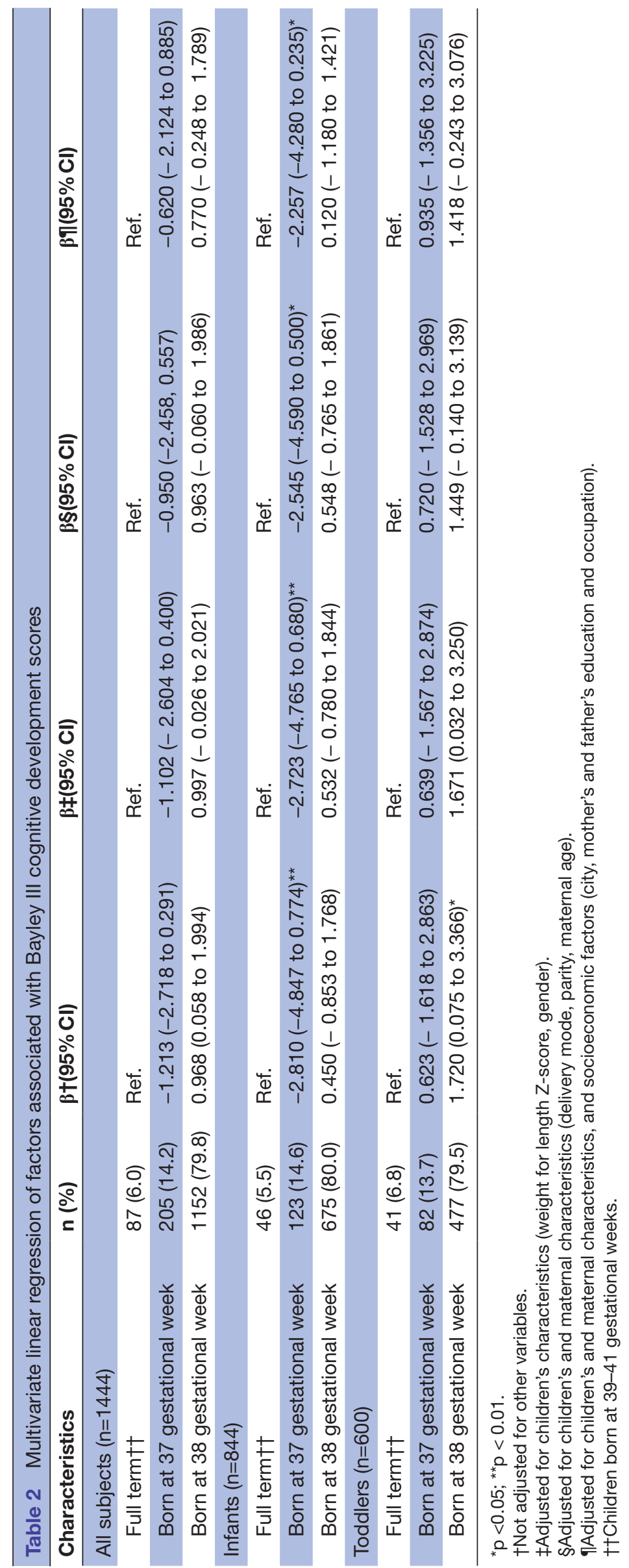

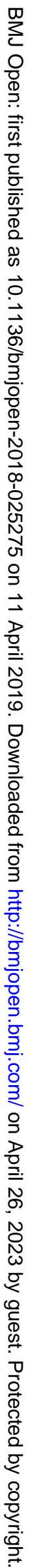


early-term pregnancies (37 weeks of gestation). When gestational age in days was classified as gestational weeks, the mortality for children born at 37 weeks of gestation was higher compared with later-term births, ${ }^{17}{ }^{31-33}$ however, children born at 38 weeks of gestation was not associated with an increased mortality. Thus, the true underlying problems for children born in week 37, remains unknown. Our findings, combined with these studies, also provide the evidences for the categorisation of early-term births. Close monitoring for any signs of developmental problems is of the utmost importance in children born at 37 gestational weeks.

Interestingly, in our study, the problems associated with early-term birth was not found in toddlers (aged between 17 months and 48 months), possibly due to the fact that the family parenting environment had a greater impact on long-term outcomes, which 'weakened' the association between early-term birth and cognitive development. A previous study showed that the quality of stimulation in the family environment is crucial for the child's cognitive development. ${ }^{34} \mathrm{~A}$ randomised control trial suggested that intervention on family environment and maternal competency has positive effects on child development (including cognitive and motor development). ${ }^{35} \mathrm{In}$ China, the effects of home and educational environments can promote the motor performance in preschoolers. ${ }^{36}$

\section{CONCLUSIONS}

Our study showed that the cognitive development scores for children born at 37 gestational weeks were significantly lower than those born at 39-41 gestation weeks. Therefore, healthcare professionals need to be more aware of the potential short-term and long-term care requirements of early-term children. Close monitoring for any signs of health and developmental problems in early-term children born at 37 gestational weeks can allow the early detection and timely treatment of borderline abnormalities, as well as prevent any potential negative health outcomes. However, because the sample size of our study was relatively small, and the results were not consistent across different age groups. Only early cognitive development was affected by early-term birth, which may provide limited evidence for public health. Further studies are needed to verify these results.

Moreover, although we examined a number of potential confounders, several other confounding factors were not measured. For instance, fetal distress, hypertensive disorder complicating pregnancy and gestational diabetes mellitus which may affect offspring's cognitive development according to the literature. These maternal and obstetric factors for early-term deliveries were not available in our study, and these factors will be considered in our further research. Furthermore, the cognitive developmental scores of children in our study are all normal (above 80 points), possibly because we selected singletons born at term birth who were mostly at low risk.
Acknowledgements The authors wish to thank all researchers and medical practitioners who participated in this study for the distribution and collection of the questionnaires, as well as administrating the cognitive scale testing for children. We also thank Bing Wang for acquiring the Research Translation License Agreement of the Bayley-3 Cognitive Scale.

Contributors JH, JS, ZC and JG contributed to the study design and drafting of the paper. XD and SL were responsible for literature search, quality control of the testing and data collection. WD and GG revised the paper and approved the finalised manuscript submission.

Funding National Natural Science Foundation of China under Grant (81673179, 81402687), the Shenkang Hospital Development Center under Grant(SHDC12016239) and the Science and Technology Commission of Shanghai Municipality under Grant (18140903100).

Competing interests None declared.

Patient consent for publication Parental/guardian consent obtained.

Ethics approval The study received ethical approval from the Local Committee of Soochow University, China (201101).

Provenance and peer review Not commissioned; externally peer reviewed.

Data sharing statement Datasets generated and/or analysed during the current study available from the corresponding author on reasonable request.

Open access This is an open access article distributed in accordance with the Creative Commons Attribution Non Commercial (CC BY-NC 4.0) license, which permits others to distribute, remix, adapt, build upon this work non-commercially, and license their derivative works on different terms, provided the original work is properly cited, appropriate credit is given, any changes made indicated, and the use is non-commercial. See: http://creativecommons.org/licenses/by-nc/4.0/.

\section{REFERENCES}

1. Sengupta S, Carrion V, Shelton J, et al. Adverse neonatal outcomes associated with early-term birth. JAMA Pediatr 2013;167:1053.

2. Spong CY. Defining "Term" Pregnancy. JAMA 2013;309:2445.

3. Martin JA, Hamilton BE, Sutton PD, et al. Births: final data for 2007. Natl Vital Stat Rep 2010;58:1-85.

4. Martin JA, Hamilton BE, Ventura SJ, et al. Births: final data for 2009. Natl Vital Stat Rep 2011;60:1-70.

5. Mally PV, Agathis NT, Bailey SM. Early term infants are at increased risk of requiring neonatal intensive care. World $\mathrm{J}$ Pediatr 2016;12:76-81.

6. Craighead DV. Early term birth: understanding the health risks to infants. Nurs Womens Health 2012;16:136-44. quiz 145.

7. Schonhaut L, Armijo I, Pérez M. Gestational age and developmental risk in moderately and late preterm and early term infants. Pediatrics 2015;135:e835-e841.

8. Rabie NZ, Bird TM, Magann EF, et al. ADHD and developmenta speech/language disorders in late preterm, early term and term infants. J Perinatol 2015;35:660-4.

9. Goyal NK, Attanasio LB, Kozhimannil KB. Hospital care and early breastfeeding outcomes among late preterm, early-term, and term infants. Birth 2014;41:330-8.

10. Chan E, Leong P, Malouf R, et al. Long-term cognitive and school outcomes of late-preterm and early-term births: a systematic review. Child: Care, Health Dev 2016;42:297-312.

11. Richards JL, Drews-Botsch C, Sales JM, et al. Describing the Shape of the Relationship Between Gestational Age at Birth and Cognitive Development in a Nationally Representative U.S. Birth Cohort. Paediatr Perinat Epidemiol 2016;30:571-82.

12. Noble KG, Fifer WP, Rauh VA, et al. Academic achievement varies with gestational age among children born at term. Pediatrics 2012;130:e257-e264.

13. Rose O, Blanco E, Martinez SM, et al. Developmental scores at 1 year with increasing gestational age, 37-41 weeks. Pediatrics 2013;131:e1475-e1481.

14. van Batenburg-Eddes T, de Groot L, Arends L, et al. Does gestational duration within the normal range predict infant neuromotor development? Early Hum Dev 2008;84:659-65.

15. Quigley MA, Poulsen G, Boyle E, et al. Early term and late preterm birth are associated with poorer school performance at age 5 years: a cohort study. Arch Dis Child Fetal Neonatal Ed 2012;97:F167-F173.

16. Chan E, Quigley MA. School performance at age 7 years in late preterm and early term birth: a cohort study. Arch Dis Child Fetal Neonatal Ed 2014;99:F451-F457. 
17. Reddy UM, Bettegowda VR, Dias T, et al. Term pregnancy: a period of heterogeneous risk for infant mortality. Obstet Gynecol 2011;117:1279-87.

18. Engle WA. Morbidity and mortality in late preterm and early term newborns: a continuum. Clin Perinatol 2011;38:493-516.

19. Cs W, Sun Y, Nohr EA, et al. Trends in All-Cause Mortality across Gestational Age in Days for Children Born at Term. PloS one 2015;10:e0144754.

20. Yang S, Platt RW, Kramer MS. Variation in child cognitive ability by week of gestation among healthy term births. Am J Epidemiol 2010;171:399-406.

21. Hambleton RK, Patsula L. Increasing the validity of adapted tests: Myths to be avoided and guidelines for improving test adaptation practices. Journal of Applied Testing Technology 1999;1:1-13.

22. Herdman M, Fox-Rushby J, Badia X. A model of equivalence in the cultural adaptation of HRQoL instruments: the universalist approach. Qual Life Res 1998;7:323-35.

23. Kinney HC. The near-term (late preterm) human brain and risk for periventricular leukomalacia: a review. Semin Perinatol 2006;30:81-8.

24. Hensch TK. Critical period plasticity in local cortical circuits. Nat Rev Neurosci 2005;6:877-88.

25. Kapellou O, Counsell SJ, Kennea N, et al. Abnormal cortical development after premature birth shown by altered allometric scaling of brain growth. PLoS Med 2006;3:e265.

26. Ip S, Chung M, Raman G, et al. Breastfeeding and maternal and infant health outcomes in developed countries. Evid Rep Technol Assess 2007;153:1-186.

27. Quigley MA, Hockley C, Carson C, et al. Breastfeeding is associated with improved child cognitive development: a population-based cohort study. J Pediatr 2012;160:25-32.
28. Boucher O, Julvez J, Guxens M, et al. Association between breastfeeding duration and cognitive development, autistic traits and ADHD symptoms: a multicenter study in Spain. Pediatr Res 2017;81:434-42.

29. Girard LC, Doyle O, Tremblay RE. Breastfeeding, Cognitive and Noncognitive Development in Early Childhood: A Population Study. Pediatrics 2017;139:e20161848.

30. Koh K. Maternal breastfeeding and children's cognitive development. Soc Sci Med 2017;187:101-8.

31. Wu CS, Sun Y, Nohr EA, et al. Trends in All-Cause Mortality across Gestational Age in Days for Children Born at Term. PLoS One 2015;10:e0144754.

32. Crump C, Sundquist K, Winkleby MA, et al. Early-term birth (37-38 weeks) and mortality in young adulthood. Epidemiology 2013;24:270-6.

33. Zhang $X$, Kramer MS. Variations in mortality and morbidity by gestational age among infants born at term. $J$ Pediatr 2009;154:358-62.

34. Andrade SA, Santos DN, Bastos AC, et al. [Family environment and child's cognitive development: an epidemiological approach]. Rev Saude Publica 2005;39:606-11.

35. Sierau S, Dähne V, Brand T, et al. Effects of Home Visitation on Maternal Competencies, Family Environment, and Child Development: a Randomized Controlled Trial. Prev Sci 2016;17:40-51.

36. Hua J, Duan T, Gu G, et al. Effects of home and education environments on children's motor performance in China. Dev Med Child Neurol 2016;58:868-76. 